\title{
Language Proficiency for Careers in Tourism and Learning Different Second Foreign Languages
}

\author{
Nikolina Božinović*, Joško Sindik** \\ Received: June 2013 | Accepted: August 2013
}

\begin{abstract}
This paper attempts to explore differences in perceptions of students from the American College of Management and Technology (ACMT) on the importance of knowledge of various foreign languages in tourism, according to the types of second foreign languages that they learned. A total of 107 participants that are currently attending American College of Management and Technology in Dubrovnik were examined by a questionnaire, designed by the authors of this paper. Key finding in this research is the fact that students consistently consider knowledge of foreign languages in general important, while the type of second foreign language that participants learned didn't appear to be an important factor in any of hospitality services, institutions or types of tourism. The results obtained could help in raising the awareness of the importance of the role of learning and teaching foreign languages, with a potential consequence of developing and promoting tourism in Dubrovnik and Croatia in general.
\end{abstract}

Keywords: choice of second language, communicative competence

\section{Introduction}

With the continued expansion of the European Union, European language policies are moving towards the teaching of 'at least two foreign languages from a very early age' and describe the knowledge of foreign languages as a 'basic skill' (Euridyce 2005, in Fernandez, 2008). The proficiency in multiple foreign languages is a basic assumption for successful communication in tourism. All European educational systems are attaching ever-increasing importance to the learning of foreign languages. There is a dire need to educate multilingual and multicultural individuals in a context where the linguistic consequences of globalization are more and more evident. The globalization process is forcing European educational systems to pay more attention to the learning of foreign languages. Therefore European schools and institutions of higher education are offering courses taught in foreign languages, exposing students to teaching through the medium of foreign language.

According to the Common European Framework of Reference for Languages (2005) communicative language competence is seen as a key competence in modern foreign lan-

* American College of Management and Technology, Dubrovnik, Croatia

** Institute for Anthropological Research, , Ljudevita Gaja 32, Zagreb, Croatia, Corresponding author: jsindik@inantro.hr 
guage teaching. Recent theoretical and empirical research on communicative competence is largely based on three models of communicative competence: the model of Canale and Swain, the model of Bachmann and Palmer and the description of components of communicative language competence in the Common European Framework of Reference for Languages (Bagaric et al., 2007). One of the most popular approaches of communicative competence (Canale and Swain, I980, in Bagarić et al., 2007) defines this competence as knowledge and skills necessary for communication. Language competence or linguistic competence refers to the knowledge of and the ability to use language resources to form well structured messages, while the sub-competences of language competence are lexical, grammatical, semantic, phonological, orthographic and orthoepic competence. Sociolinguistic competence refers to the possession of knowledge and skills for an appropriate language use in a social context. It relates primarily to an understanding of other cultures, register, accent, dialects, and interaction skills.

In the field of tourism, beside the communicative language ability it is extremely important to also develop the so-called intercultural competence, or the ability of successful communication between members of different cultures. The process of globalization has indeed opened many doors thus forcing us to recognize the existing differences and diversities of people living in the European Union. Still, it is an ongoing process to learn how to recognize, respect and learn to appreciate those differences. Knowledge, awareness and understanding of the relation between the 'world of origin' and the 'world of the target community' produce this intercultural awareness. It is, of course, important to note that intercultural awareness includes an awareness of regional and social diversity in both worlds. This process is also enriched by the awareness of a wider range of cultures than those carried by the learner's LI (first language) and L2 (second language). This wider awareness helps to place both languages in context. In addition to objective knowledge, intercultural awareness covers an awareness of how each community appears from the perspective of the other, often in the form of national stereotypes. Intercultural skills and different know-how skills include the ability to bring the culture of origin and the foreign culture into relation with each other. It also helps develop cultural sensitivity and the ability to identify and use a variety of strategies to contact those from other cultures. Those strategies should also include the capacity to fulfill the role of cultural intermediary between one's own culture and the foreign culture and to deal effectively with intercultural misunderstanding and conflict situations as well as the ability to overcome stereotyped relationships (Common European Framework of Reference for Languages, 2OOI). It is evident that in the field of tourism and hospitality it is extremely important to develop not only communicative language ability but also the intercultural competence, or the ability of successful communication between members of different cultures. As indicated in the thematic title of this year's conference, tourism and hospitality are clearly seen as drivers of transition. The authors of this article consider that language is the vehicle they use in this process of transition.

\section{Literature Review}

Lasagabaster (2008) points out that one of the most important issues in many European education systems is whether it is better to start foreign language teaching at an early age, or whether it is better to include content and language integrated learning at a later stage without establishing an early first contact with the foreign language. The research undertaken in 
naturalistic settings confirms that students who start learning foreign language at an early age ultimately achieve higher competence in the L2. Numerous empirical studies in the field of Second Language Acquisition (SLA) have shown that children who begin learning a second language before adolescence exhibit more native-like pronunciation and are more likely to become fluent speakers. The critical period hypothesis states that there is a period when language acquisition takes place naturally and effortlessly (Ellis, I986:IO7). In most cases, if a person is not exposed to a language during the critical period, he or she will never be able to speak the language as fluently as someone who learned a language normally. It is argued that the optimum age for language acquisition falls within the first ten years of life. During this period the brain retains plasticity, but with the onset of puberty this plasticity begins to disappear. Recent findings in brain research indicate that the specialized functions of specific regions of the brain are not fixed at birth but are shaped by experience and learning. This means that we should promote the importance of learning more than one foreign language in the early age. It must, however, be emphasized that L2 learners vary considerably both in how quickly they learn and how successful they are. The evidence suggests that the explanation for this lies in differences in personal and general factors. Second language (L2) learners vary on a number of dimensions that have to do with personality, motivation, learning style, learning strategies, aptitude and age (Dörnyei, 2005).

Language thus becomes the true manifestation of a culture and people's value systems. Language is the most important medium of human communication, since through it we express information, ideas, emotions, attitudes and so many other things (Petrovska, 2OIO). Due to multiple functions and roles of language in humans and in our societies as a whole it is crucial that we all recognize that the world we all live in is influenced by a series of interlocking cultures, and it is not a unique, uniformed cultural model. So, communicative competence without the existence of awareness of cultural dimensions in the use of any language is not complete. In the process of learning a new language it is important to be aware of its cultural aspect(s), because the knowledge of other cultures helps a learner to learn a certain language and to assess cultural values of that language (Ellis, 2005; Williams and Burden, I999, in Luka, 2007). According to Byram (2000, in Luka, 2007), intercultural competence includes attitude, knowledge, interpretation and related skills, various discovery and interaction skills, as well as critical awareness of culture or political education. In order to develop intercultural competence, students should not only learn a foreign language, but such a process should also include intercultural training and intercultural exchange of ideas. It is evident that the knowledge and the skills acquired in this learning process will highly contribute to the development of tourism and hospitality services in general.

Students of tourism, hospitality and management also have to acquire theoretical and practical cultural knowledge, which can be gained through intercultural communication and the development of intercultural competence. Intercultural competence is mostly referred to as an ability to see and understand differences in one's own and other people's culture, to accept them and accordingly react (in conversation and behavior, treating people in a way which is not offending or insulting to the members of other cultures). At the same time this competence includes the knowledge of one's own nation and culture, and the awareness of its values as well as the necessity of their preservation (Luka, 2007). If we transfer this into the area of tourism and hospitality, and try to distinguish what is important to know about the language that hotel and restaurant employees use, we will soon realize that it is not only the knowledge of the grammar and vocabulary that they need to apply but they need to be aware of the importance of the socio-cultural aspect as well (or, as some linguists call it, its 
pragmatics) (Petrovska, 2OIO). Although their grammatical and their lexical competence of a foreign language may be outstanding it still can cause cultural misunderstanding, or a final failure in communication with native speakers. Petrovska (2OIO) points out that this failure may be a result of lack of knowledge of cultural differences between the two (or more) societies, or the influence of their mother tongue and direct transfer of meaning in the other language. They simply may not know how to handle cultural differences or how to see what they are in the first place. This, for example, is of utmost importance for the communicative competence of HR employees.

From the aspect of the aforementioned importance of foreign languages for careers in tourism, the objective of our study was to identify the differences in the importance of knowledge of selected foreign languages in improving the overall offer in the hospitality area of Dubrovnik, according to the types of second foreign languages that participants learned. Additionally, we are also interested in differences according to the types of second foreign languages that participants learned to the grade of the importance of this knowledge in different tourist categories in the overall tourist offer, such as cultural tourism, congress tourism, nautical tourism and ecotourism as well as to identify which foreign languages are important for specific types of tourism. The differences according to the types of second foreign languages that participants learned are also considered in the identification of the importance of foreign language skills in different institutions and organizations, such as hotels, restaurants, institutions of local government, tourist board and public sector that are responsible for the development of the city of Dubrovnik as a tourist destination. Finally, we make an attempt to find differences according to the types of second foreign languages that participants learned in the difficulty of learning of foreign languages. Our initial hypothesis was that we'll find no differences according to the types of second foreign languages that participants learned in any of previously defined fields. Namely, differences we might expect given the choice of German and Italian as a second foreign language can indicate constructive consideration of the current situation in the tourism industry, but also the perspective of their own careers. However, all participants have the same education level and mostly live in the same town, and are equally aware of the importance of foreign language skills in all aspects of tourism services, regardless of the choice of other foreign languages that are currently most needed (compared to the composition of tourists in Dubrovnik region). So, we can't have proper arguments for expecting differences in evaluation of the factors connected with the importance of foreign languages for careers in tourism, according to the types of second foreign languages that participants learned.

\section{Methodology}

\section{Instrument}

The importance of knowledge of foreign languages was examined by a questionnaire that was designed by the authors of this paper. This questionnaire is a semi-structured questionnaire, divided into 6 categories of questions which examine the importance of knowledge of foreign languages in specific areas of tourism. A five-point scale was used to evaluate the degree of importance of foreign languages in each tourism category (from I- 'not important' to 5- 'most important'). In the first category of the questionnaire the participants had to rate the importance of knowledge of a particular foreign language in improving the over- 
all offer in hospitality services in Dubrovnik. In the second category the participants had to rate the degree of importance of four categories of tourism (cultural, congress, nautical and ecotourism) in the overall offer. In the third category the participants had to answer which foreign languages are important for specific types of tourism, and in the fourth category the participants had to rate the degree of importance of foreign languages in mass tourism and elite tourism. In the fifth category the participants had to rate the importance of knowledge of foreign languages in different institutions and organizations that are responsible for the development of the city of Dubrovnik as a tourist destination, i.e. in hotels, restaurants, coffee bars, institutions of local government and self-government, tourist board and public sector (medical institutions, public transportation, banks etc.) In the last category, participants were given a task to rank the languages according to the degree of difficulty (I- 'most difficult to learn', 2- 'difficult', 3- 'neither difficult nor easy', 4- 'easy', 5 - 'easiest'). The questionnaire also provided some demographic data on the participants (gender, age, language learning degree, mother tongue, first (LI) and second (L2) foreign language.

\section{Participants}

A total of IO7 participants that are currently attending the American College of Management and Technology in Dubrovnik participated in this survey. There were 58 male $(54.2 \%)$ and 49 female (45.8\%) participants. 46 of them (43\%) were senior students, while 6I of them (57\%) were students in their third year of study (junior students). It is important to mention that all participants are enrolled in Hospitality and Service Management Program (HSM). 89 participants $(83.2 \%)$ were native speakers of Croatian, while I8 participants (I6.8\%) were native speakers of one of the following languages: Bosnian, English, Macedonian, Montenegrin, Albanian, Serbian, German, Norwegian and Italian. For 9I participants (85\%) English was their first foreign language. 28 participants (26.2\%) took German as their second foreign language while 40 participants took Italian (37.4\%) as their second foreign language. II participants (IO.3\%) took French as their second foreign language, 22 participants (20.6\%) took Spanish as their second foreign language, 5 participants learned English (4.7\%) as their second foreign language, and for I participant (0.9\%) Russian was his second foreign language. Most of our participants had already previously studied relative foreign languages: 38 participants $(35.5 \%)$ stated that they had been studying their second foreign language for more than 6 years, 33 participants (30.8\%) stated they had been studying their second foreign language for more than two years, while I6 of them (I5\%) stated that they had been studying their second foreign language for already more than 4 years. As to an answer to the question how many languages they speak, 52 participants (48.6\%) declared to speak two foreign languages, 29 participants (27.I\%) three foreign languages, while I2 of them (II.2\%) declared to speak four foreign languages.

\section{Data collection and analysis}

All the data in this questionnaire were collected during regular classes at the American College of Management and Technology and its participants were not informed beforehand about the survey. The survey was anonymous, in order to provide sincere and honest answers to questions. Data analysis was performed using t-test for independent samples and Chi-square test and the data from the questionnaire were analyzed using statistical package SPSS II.O. 


\section{Results and Discussion}

Differences according to the types of second foreign languages that participants learned in the importance of knowledge of foreign languages in the improvement of the overall offer in hospitality services in Dubrovnik, were analyzed. As shown in Table I, we haven't found any statistically significant differences in the role of the most important foreign language in the hospitality area in Dubrovnik. All participants stated that English is the most important in the improvement of the overall offer in hospitality services.

Table 1. Differences in the importance of knowledge of foreign languages in the improvement of the overall offer in hospitality services according to the types of second foreign languages that participants learned

\begin{tabular}{|c|c|c|c|c|c|c|}
\hline $\begin{array}{l}\text { Second foreign } \\
\text { language }\end{array}$ & $\begin{array}{c}\text { t-test } \\
(\mathrm{df}=105)\end{array}$ & $P$ & $\frac{M}{\text { German, Italian }}$ & $\begin{array}{c}\sigma \\
\text { German, Italian }\end{array}$ & $\begin{array}{l}\text { M } \\
\text { French, Spanish, } \\
\text { English, Russian }\end{array}$ & $\begin{array}{c}\quad \sigma \\
\text { French, Spanish, } \\
\text { English, Russian }\end{array}$ \\
\hline English & .156 & $>.20$ & 4.85 & .625 & 4.83 & .526 \\
\hline German & -.479 & $>.20$ & 3.66 & 1.048 & 3.75 & .856 \\
\hline Italian & -1.522 & $>.20$ & 3.57 & 1.078 & 3.87 & .853 \\
\hline French & -.978 & $>.20$ & 3.19 & 1.096 & 3.40 & 1.092 \\
\hline Spanish & -.696 & $>.20$ & 3.40 & .970 & 3.53 & .929 \\
\hline Russian & -.624 & $>.20$ & 3.13 & 1.115 & 3.27 & 1.177 \\
\hline
\end{tabular}

Legend: $M=$ Mean; $\sigma=$ Standard Deviation

As indicated in Table 2, there are no statistically significant differences according to the types of second foreign languages that participants learned in the importance of the types of tourism. However, for congress tourism we can observe non-significant trend of higher means in students that learn German and Italian as second languages. This fact confirms our initial hypothesis that English has become a global language. It is already a well-known fact that many millions of people in countries all over the world are learning English which more and more comes to be seen as a 'universal basic skill' or 'lingua franca'.

Table 2. Differences in the importance of the types of tourism according to the types of second foreign languages that participants learned

\begin{tabular}{|c|c|c|c|c|c|c|}
\hline $\begin{array}{l}\text { Second foreign } \\
\text { language }\end{array}$ & $\begin{array}{c}\text { t-test } \\
(\mathrm{df}=105)\end{array}$ & $P$ & $\stackrel{\text { M }}{\text { German, Italian }}$ & $\begin{array}{c}\sigma \\
\text { German, Italian }\end{array}$ & $\begin{array}{l}\quad \text { M } \\
\text { French, Spanish, } \\
\text { English, Russian }\end{array}$ & $\begin{array}{l}\quad \sigma \\
\text { French, Spanish, } \\
\text { English, Russian }\end{array}$ \\
\hline Cultural tourism & -.493 & $>.20$ & 1.15 & .659 & 1.22 & .761 \\
\hline Congress tourism & 1.700 & $>.05$ & 1.11 & .429 & 1.00 & .000 \\
\hline Nautical tourism & -.317 & $>.20$ & 1.34 & .867 & 1.40 & 1.077 \\
\hline Ecotourism & 1.101 & $>.20$ & 1.21 & .750 & 1.08 & .334 \\
\hline
\end{tabular}

Legend: $M=$ Mean; $\sigma=$ Standard Deviation

There are no statistically significant differences according to the types of second foreign languages that participants learned in the importance of the knowledge different foreign languages for different types of tourism. However, for ecotourism we can observe non-significant trend of higher means in students that learn German and Italian as second languages (Table 3). 
Table 3. Differences in the importance of the knowledge different foreign languages for different types of tourism according to the types of second foreign languages that participants learned

\begin{tabular}{|c|c|c|c|c|c|}
\hline Second foreign language & $\begin{array}{l}\text { not important or } \\
\text { slightly important }\end{array}$ & $\begin{array}{l}\text { moderately } \\
\text { important }\end{array}$ & $\begin{array}{c}\text { very } \\
\text { important }\end{array}$ & $\begin{array}{c}\text { most } \\
\text { important }\end{array}$ & Chi square \\
\hline & \multicolumn{5}{|c|}{ Important for development of culture tourism } \\
\hline German, Italian & 1 & 6 & 14 & 47 & .915 \\
\hline \multirow[t]{2}{*}{ French, Spanish, English, Russian } & 1 & 2 & 10 & 26 & \\
\hline & \multicolumn{5}{|c|}{ Important for development of nautical tourism } \\
\hline German, Italian & 6 & 19 & 25 & 18 & 2.286 \\
\hline \multirow[t]{2}{*}{ French, Spanish, English, Russian } & 4 & 13 & 12 & 10 & \\
\hline & \multicolumn{5}{|c|}{ Important for development of ecotourism } \\
\hline German, Italian & 9 & 19 & 25 & 15 & 5.472 \\
\hline \multirow[t]{2}{*}{ French, Spanish, English, Russian } & 7 & 14 & 9 & 9 & \\
\hline & \multicolumn{5}{|c|}{ Important for development of congress tourism } \\
\hline German, Italian & 4 & 17 & 30 & 17 & .958 \\
\hline French, Spanish, English, Russian & 1 & 9 & 18 & 11 & \\
\hline
\end{tabular}

Note: all Chi-square tests are non-significant

As indicated in Table 4, there are no statistically significant differences according to the types of second foreign languages that participants learned in the importance of the knowledge foreign languages in elite and mass tourism.

Table 4. Differences in the importance of the knowledge of foreign languages in elite and mass tourism according to the types of second foreign languages that participants learned

\begin{tabular}{|l|r|r|r|r|r|r|}
\hline $\begin{array}{l}\text { Second foreign } \\
\text { language }\end{array}$ & $\begin{array}{c}\mathrm{t} \text {-test } \\
(\mathrm{df}=105)\end{array}$ & $\mathrm{P}$ & $\begin{array}{c}\mathrm{M} \\
\text { German, Italian }\end{array}$ & $\begin{array}{c}\sigma \\
\text { German, Italian }\end{array}$ & $\begin{array}{c}\text { French, Spanish, } \\
\text { English, Russian }\end{array}$ & $\begin{array}{c}\sigma \\
\text { French, Spanish, } \\
\text { English, Russian }\end{array}$ \\
\hline Mass tourism & -1.079 & $>.10$ & 3.81 & 1.329 & 4.07 & 1.087 \\
\hline Elite tourism & -.982 & $>.20$ & 4.70 & .623 & 4.82 & .567 \\
\hline
\end{tabular}

Legend: $M=$ Mean; $\sigma=$ Standard Deviation

As indicated in Table 5, there are no statistically significant differences according to the types of second foreign languages that participants learned in the importance of the knowledge of foreign languages in different institutions and organizations.

Table 5. Differences in the importance of the knowledge of foreign languages in different institutions and organizations according to the types of second foreign languages that participants learned

\begin{tabular}{|l|r|r|r|r|r|r|}
\hline $\begin{array}{l}\text { Second foreign } \\
\text { language }\end{array}$ & $\begin{array}{c}\text { t-test } \\
(\mathrm{df}=105)\end{array}$ & $\mathrm{P}$ & $\begin{array}{c}\text { M } \\
\text { German, Italian }\end{array}$ & $\begin{array}{c}\sigma \\
\text { German, Italian }\end{array}$ & $\begin{array}{c}\text { French, Spanish, } \\
\text { English, Russian }\end{array}$ & $\begin{array}{c}\sigma \\
\text { French, Spanish, } \\
\text { English, Russian }\end{array}$ \\
\hline $\begin{array}{l}\text { hotels, restaurants, } \\
\text { coffee bars }\end{array}$ & .523 & $>.20$ & 4.71 & .600 & 4.64 & .628 \\
\hline $\begin{array}{l}\text { institutions of local } \\
\text { government and } \\
\text { self-government }\end{array}$ & -1.028 & $>.20$ & 3.94 & .976 & 4.13 & .864 \\
\hline tourist board & .660 & $>.20$ & 4.66 & .637 & .745 & .786 \\
\hline public sector & -.114 & $>.20$ & 4.16 & & & \\
\hline
\end{tabular}

Legend: $M=$ Mean; $\sigma=$ Standard Deviation 
There are no statistically significant differences according to the types of second foreign languages that participants learned in the importance of the knowledge of certain foreign languages in different services (tourist agency employees, receptionists, cooks, chambermaids, hotel managers and public sector employees, waiters, taxi drivers).

One of the aims of our study was also to determine differences according to the types of second foreign languages that participants learned in the degree of difficulty in learning various foreign languages. Our participants were asked to rank the following foreign languages: English, French, German, Spanish and Italian according to the given scale (from most difficult to learn to easiest to learn). Our research revealed that there are no any statistically significant differences in the difficulty of learning certain foreign languages, in any of categories, according to the types of second foreign languages that participants learned (Table 6).

Table 6. Differences in the difficulty of learning certain foreign languages according to the types of second foreign languages that participants learned

\begin{tabular}{|l|c|c|c|c|c|c|c|}
\hline Second foreign language & English & German & Italian & French & Spanish & Russian & Chi square \\
\hline & \multicolumn{7}{|c|}{ The hardest to learn language } \\
\hline German, Italian & 2 & 24 & 2 & 39 & 1 & & 3.729 \\
\hline French, Spanish, English, Russian & 2 & 20 & 1 & 16 & & & \\
\hline & \multicolumn{7}{|c|}{ The easiest language to learn } \\
\hline German, Italian & 54 & 1 & 8 & 5 & & & 6.067 \\
\hline French, Spanish, English, Russian & 25 & & 5 & 9 & & & \\
\hline
\end{tabular}

Note: all Chi-square tests are non-significant

In general, the type of second foreign language that students learned doesn't appear to be an important factor for different aspects of working in the sector of tourism. These results can be observed from the point of view that the participants have the same education level and mostly live and study in the same town. Consequently, they are equally aware of the importance of foreign language skills in all aspects of tourism services, regardless of the choice of learning other foreign languages that are currently most needed in the Dubrovnik region. The best-fit conceptual framework for describing these results can be intercultural competence, or the ability of successful communication between members of different cultures, that we have mentioned in the Introduction chapter. Young people (especially highly educated, such as our participants are) are aware of the substantial need to recognize the existing differences and diversities of people living in European Union (Luka, 2007). As inherent part, learning a new language carries out the knowledge of other, through cultural values of the language (Ellis, 2005). Students that learn second foreign language simultaneously develop intercultural competence, through non-formal intercultural training and intercultural exchange of ideas. Reasoning in this direction, the authors of this paper are of the opinion that encouraging people to understand other languages and cultures will help to improve communication and understanding between them, while improving this understanding can be beneficial for the development of the tourism offer and promotion. However, as Lasagabaster (2008) points out, one of the most important issues in many European education systems is an attempt to ensure that children start learning second (and more) foreign language(s) at an early age, when language acquisition takes place naturally and effortlessly (Ellis, 2005). But raising awareness of such initiatives has to be widespread in the whole population, not only on those families and individuals with academic ambitions, or with direct interest in tourism sector. 
The main shortcoming of the research is relatively small and specific (non-representative for general population) sample of participants (students of ACMT in Dubrovnik). However, the same sample of participants can be considered as an advantage of this research: specifically educated population can better reflect some real important aspects in tourism management. This survey has indicated that foreign language proficiency is very important, so our main finding can be considered as a trend that all the students perceive foreign language proficiency as important in tourism business in general. However, in the improvement of the overall offer in the hospitality area in Dubrovnik and the authors of this article strongly recommend learning of other foreign languages beside English.

\section{Conclusion}

The main finding in this research is the argument that students from the American College of Management and Technology in Dubrovnik consistently consider knowledge of foreign languages in general important for working in tourism. The type of second foreign language that participants learned in this study is not revealed as an important factor in any of hospitality services, institutions or types of tourism. There are no perceived difficulties in learning different foreign languages. These facts have supported our initial hypothesis. In other words, the homogeneity of the participants on their education level and their place of study could diminish possible differences in the type of second foreign language that participants have learned. The results obtained could help in raising the awareness of the importance of the role of learning and teaching foreign languages in general, but especially for tourism purposes. Of course, a potential consequence is the possibility of developing and promoting tourism in Dubrovnik and Croatia in general. The authors suggest that it would be beneficial to investigate the importance of knowledge of different other foreign languages in various professions in tourism, with different achieved levels of education. Aimed education of other foreign languages can be planned as the intervention project in some (for example Dubrovnik) area, while the effects of such interventions are just some of the aspects that could be studied in future research.

\section{References}

Bagarić, V. and Mihaljević Djigunović, J. (2007). Defining communicative competence, Metodika, 8 (I), 84-93.

Common European Framework of Reference for Languages: Learning, Teaching, Assessment. (2OOI). Council of Europe. Cambridge University Press.

Dörnyei, Z. (2OO5). The Psychology of the Language Learner. Individual differences in Second Language Acquisition. London: Lawrence Erlbaum Associates, Inc.

Ellis, R. (1986). Understanding Second Language Acquisition. Oxford: Oxford University Press.

Fernandez, S. (2008). Teaching and Learning Languages Other than English (LOTE) in Victorian Schools, http://www.eduweb.vic.gov.au/edulibrary/public/publ/research/ publ/language-learning-report.pdf [Accessed the 27th of April 2OII, IO:22]

Lasagabaster, D. (2008). Foreign Language Competence in Content and Language Integrated Courses, The Open Applied Linguistics Journal, I, 3I-42. 
Luka, I. (2007). Development of Student's English for Special Purposes Competence in Tourism Studies at Tertiary Level. The paper presented at the International bilingual conference "Assessing language and (inter-) cultural competences in Higher Education" in Finland, the University of Turku, 3O-3I. April, 2OII http://www.turiba.lv/uploaded_files/Mig_ Komm/Language_competence.pdf [Accessed the 27th of April 2OII, I5:3I]

Petrovska, I. (2OIO). Teaching and Learning Pragmatics: Speech Strategies for HR Employers, Faculty of Tourism and Hospitality Management in Opatija. Bienniall International Congress. Tourism and Hospitality Industry, II42-II49. 